\title{
Os editoriais em pauta ${ }^{1}$
}

\author{
Davys Sleman de Negreiros ${ }^{2}$
}

1 Trabalho apresentado no I Seminário Regional da Asociación Latinoamericana de Investigadores de la Comunicación (Alaic) - Bacia Amazônica, em 2011.

2 Mestre em ciências sociais pela Universidade Federal de São Carlos (UFSCar) e professor do Instituto Federal de Educação, Ciência e Tecnologia de Rondônia, em Cacoal. davys.negreiros@ifro.edu.br 


\section{Resumo:}

Este trabalho está baseado na análise de conteúdo (sinteticamente, consiste em isolar determinados elementos - palavras, frases, imagens, símbolos etc. - de um conjunto de mensagens, em função de certas categorias previamente determinadas) de editoriais (não assinados) publicados no período das eleições presidenciais de 1998 em jornais que estão entre os líderes de tiragem de seu gênero no país e que possuem uma influência nacional: Folha de S. Paulo (Folha) e O Estado de S. Paulo (Estadão). A partir dessa análise, determinou-se a agenda temática dos editoriais; realizou-se a comparação entre eles (semelhanças e diferenças); e buscou-se descobrir como se configuraram os noticiários/ editoriais e qual foi o comportamento dos temas .

\section{Palavras-chave:}

Editoriais, meios de comunicação, eleições, jornais, agenda-setting.

\section{Abstract:}

This work is based on content analysis (specifically, it is to isolate certain elements - words, phrases, images, symbols etc. - from a group of messages, according to predetermined categories) of unsigned editorials published during the period of 1998 presidential elections in newspapers that are taken forbeing those with the largest circulation of their kind in the country and those with a national influence: Folha de S. Paulo (Folha) and O Estado de S. Paulo (Estadão). As a result of the analysis, we have pointed out the thematic agenda of the editorials, we made a comparison between them (their similarities and differences), andtried to observe how the news/editorial are configured and what is the behavior of the subjects in it.

\section{Keywords:}

Editorials, media, elections, newspapers, agenda-setting. 


\section{Introdução}

Pode-se aceitar o argumento de que a propaganda/marketing, as mídias e as estatísticas (as polêmicas pesquisas de opinião) impõem-se à medida que se retrai a cena tradicional da política. Na cena brasileira, faltam principalmente os partidos, pelo menos quando se pensa teoricamente ${ }^{3}$. Desde o final dos anos 50 , eles entraram em crise de representatividade, acelerada pelo golpe militar de 1964. A reabertura política reencontrou, com o nome de partidos políticos, máquinas burocráticas que giram na órbita de seus interesses ou, então, pequenas agremiações com palanques despolitizados, francamente televisivos. Esse fato torna-se compreendido, no caso brasileiro, quando realizamos uma retrospectiva de todo o movimento dos partidos políticos no Brasil - demonstrando todas as dificuldades políticas e institucionais da nossa acidentada trajetória republicana: originalmente oligárquica (1889/1930), oscilou historicamente entre a ditadura (1937/1945 e 1964/1985) e o populismo (1946/1964), até chegar ao atual experimento democrático. Nesse processo histórico, foram experimentados nada menos do que seis sistemas partidários distintos, sem praticamente nenhuma continuidade formal ou política entre eles, o que não só impediu a existência de partidos fortes como também inibiu a formação de uma cultura cívica aberta e receptiva à ação dos partidos e favorável à constituição de identidades partidárias estáveis e consistentes ao longo do tempo. Só para ter uma ideia da falta de tranquilidade e de continuidade do sistema republicano brasileiro, do "período compreendido de 1930 a 1990, tivemos um golpe ou tentativa de golpe a cada três anos"4. Assim, podemos afirmar que há um vácuo de representatividade, que num determinado momento foi preenchido pelas mídias, tendo como consequência, segundo Muniz Sodré, que, "nesses espaços mediados, trava-se

3 O partido político, a nosso ver, é uma organização de pessoas que, inspiradas por ideias ou movidas por interesses, buscam tomar o poder, normalmente pelo emprego de meios legais, e nele conservar-se para a realização dos fins propugnados; notar em relação a esse tema a obra clássica de DUVERGER, M. Os partidos políticos.Rio de Janeiro: Zahar Editores; Brasília: UnB, 1980; SARTORI, G. Partidos e sistemas partidários. Rio de Janeiro: Zahar Editores; Brasília: UnB, 1982.

$4 \quad$ Frase proferida pelo prof. dr. Francisco de Oliveira, da USP, no "Projeto Fórum de Debates - Periferia, subdesenvolvimento e radicalização antidemocrática", 2 set. 1998 - teatro Florestan Fernandes, na UFSCar. 
uma novíssima disputa eleitoral: em vez de plataformas marcantes, vantagens percentuais nas pesquisas, em vez de posições ideológicas, rostos fotogênicos ou telegênicos, em vez de representação, simulação"s.

De modo geral, persiste a preocupação de que, no espaço público configurado pela mídia, a política tende a perder o seu conteúdo próprio, e os partidos políticos, sua identidade como mediadores de interesses entre a sociedade e o Estado. Como destaca García Canclini (1990, 1995), ao ocupar o lugar das mediações que seria próprio da política, as mídias estabeleceriam uma nova diagramação dos espaços e intercâmbios urbanos. A contaminação da política pela comunicação não se esgota no deslocamento de poder ocasional pelo monopólio tendencial do ato de publicitar ou na criação de temas/atores/ cenários. A questão da adequação da política às regras e à gramática da mídia, de imediato, coloca-se no centro da análise. Ao aceitar a premissa de incorporação da comunicação como componente e momento da política contemporânea, uma vez que a mídia monopoliza tendencialmente a enunciação pública, podese considerar que a política, para incorporar a comunicação (midiática), deve resignar-se às regras e às formatações derivadas da mídia, posto que isso não só facilita sua realização como até se torna inevitável.

\section{A hipótese do agenda-setting}

A literatura pertinente às questões básicas que organizam este trabalho é a dos autores vinculados à chamada hipótese do agenda-setting ${ }^{6}$, que se filia à tradição dos estudos sobre os efeitos cognitivos da comunicação em longo prazo. O argumento central dessa literatura foi construído tendo como ponto de partida a observação do cientista político Bernard Cohen (1963, p. 120-21) de que, "na maior parte das vezes, a imprensa não tem êxito dizendo às pessoas

5 Citação coletada no Jornal do Brasil/Idéias, 3 jan. 1987.

6 Sobre o histórico e o desenvolvimento da pesquisa acerca da hipótese de agenda-setting, ver FORMIGA, F. de O. N. A evolução da hipótese de agenda-setting. Dissertação (Mestrado) - Universidade de Brasília, 2006. Mimeografado. 
como elas devem pensar. Mas tem sempre êxito dizendo aos seus leitores o que pensar". A ideia básica do agenda-setting sustenta a existência de uma correlação direta e causal entre a agenda da mídia e a agenda do público ${ }^{7}$, na medida em que, numa sociedade de massa, a percepção pública dos temas relevantes é construída tendo por base as informações veiculadas pela mídia. Desse modo, como lembra Shaw (1979, p. 96), em função do que se publica ou se veicula na mídia, o público "sabe ou ignora, presta atenção ou descura, realça ou negligencia elementos específicos dos cenários públicos". Em outras palavras, a mídia, ao descrever a realidade ou narrar acontecimentos, sugere direta ou indiretamente ao público uma lista do que é necessário discutir sobre o que se deve ter uma opinião. Por sua vez, McCombs e Shaw (1972, p. 177) chamam a atenção para o fato de que, se os meios de comunicação de massa têm uma fraca influência sobre a tendência ou intensidade das atitudes das pessoas; em contrapartida, são capazes de fixar a agenda nas campanhas políticas, influenciando o aparecimento de atitudes perante os diferentes temas políticos. Assim, e à medida que as questões em debate se tornam mais importantes do que a identidade partidária ou as linhas ideológicas, a arena política se transforma num "palco central de uma luta simbólica em torno da construção dos acontecimentos e das questões" (TRAQUINA, 1995, p. 109). Detalhando a função do agenda-setting, McCombs (1976, p. 6) afirma:

Os jornais são os principais promotores da agenda do público. Definem amplamente o âmbito do interesse público, mas os noticiários televisivos não são totalmente desprovidos de influência. A televisão tem um certo impacto, em curto prazo, na composição da agenda do público. O melhor modo de descrever e distinguir essa influência será, talvez, chamar de "agenda-setting" a função dos jornais e de "enfatização" (ou spot-lighting) a da televisão. O caráter fundamental da agenda parece, frequentemente, ser estruturado pelos jornais, ao passo que a televisão reordena ou ressistematiza os temas principais da agenda.

7 Obviamente a "agenda da mídia" é formada pelo conjunto de temas presentes na mídia em determinado período, enquanto a "agenda do público" é constituída pelo conjunto de temas que reclamam a atenção pública durante um determinado período. 
A hipótese do agenda-setting implica a ideia de que a produção de notícias demanda uma operação de enquadramento que se realiza, na rotina produtiva da imprensa, através da adoção de critérios de relevância para organizar acontecimentos, temas, aspectos e problemas. Nesses termos, a produção da notícia é, sociologicamente falando, um processo de construção da realidade, na medida em que oferece um quadro interpretativo (frame) $)^{8}$ ao público. Em função dessa abordagem, a noção de gatekeeper ${ }^{9}$ e a análise da rotina produtiva (e, naturalmente, dos critérios de "noticiabilidade") foram retomadas e revalorizadas pelo modelo do agenda-setting, bem como a análise dos efeitos cumulativos ao longo de um quadro temporal (time-frame). No estado atual, a hipótese do agenda-setting é, portanto, mais um núcleo de temas e de conhecimentos parciais, susceptível de ser, posteriormente, organizado e integrado numa teoria geral sobre a mediação simbólica e sobre os efeitos de realidade exercidos pelos mass media, do que um modelo de pesquisa definido e estável.

\section{O editorial do jornal}

No contexto da comunicação política, a hipótese do agenda-setting defende, portanto, que o papel dos media se torna importante na decisão do voto devido à crescente importância das questões (os assuntos que são discutidos) nas campanhas políticas, em detrimento da identificação partidária. Assim, escrevem McCombs e Shaw (apud TRAQUINA, 1995, p. 190): "A arte política numa democracia é, num considerável, a arte de determinar que dimensões das questões são de importância maior para o público ou podem tornar-se salientes de forma a conseguir apoio público".

8 Os antecedentes teóricos da noção de frame encontram-se em Berger e Luckmann (1976) e Goffman (1991), que, a partir da fenomenologia social de Alfred Schutz, elaboraram uma teoria da construção social da realidade na qual a análise de quadros constitui um desenvolvimento importante.

9 O gatekeeper, numa definição minimalista, é o operador que, no interior de um meio de comunicação, seleciona os temas e determina sua relevância e seu tempo de permanência na mídia. Essa função pode ser exercida por um indivíduo isolado, por uma organização ou mesmo por um conjunto institucional. Como indica Saperas (1987, p. 58), a "noção foi criada por Kurt Lewin em 1947, em 'Channels of Group Life', e foi aplicada ao estudo da informação jornalística por D.M. White, em 1950, no artigo intitulado 'The gatekeeper: acase study in the selection of news', publicado em Journalism Quarterly". McCombs e Shaw retomaram e desenvolveram o conceito para aplicá-lo no modelo do agenda-setting. 
Desse modo, o agenda-setting, por delimitar ou enquadrar certas questões e deixar de lado outras, acaba gerando e projetando uma determinada realidade ao público. Porém, para que isso ocorra, tem que haver um canal de ligação com a sociedade, e esse link são os meios de comunicação. Entre esses, sobressai o jornal ${ }^{10}$ (que possui uma maior influência de agendamento) - e, das suas várias seções, ressaltamos o editorial (que exprime a opinião do órgão e é publicado com destaque).

Os editoriais têm natureza essencialmente opinativa. Esse caráter os distingue das matérias informativas (notícias) e das recreativas (features). A denominação é usada em dois sentidos: no primeiro, mais amplo, significa todo texto dessa natureza veiculado primeiramente em jornal mas também em revista ou em qualquer outro meio de comunicação de massa; no aspecto restrito, corresponde aos textos que veiculam a opinião do editor do órgão jornalístico que os publica, operando em off. Assim, como escreve Fausto Neto (1994, p. 162):

[...] a despeito de operar numa posição que deixa o sujeito da enunciação numa linha de invisibilidade, isso não quer dizer que não o deixem, no nível do discurso, as marcas de sua presença, a saber, indícios de sua participação, não só no processo de produção, mas também no de proposição do sentido.

Em geral, os editoriais que representam a opinião do jornal não levam assinatura, pois sua autoria é atribuída à direção do órgão. Antes, porém, que o jornal evoluísse de obra mais ou menos artesanal para autêntico produto industrial, mesmo esses editoriais costumavam ser assinados pelo diretor, pelo redator principal ou pelo conselho editorial do jornal - prática subsistente até hoje, em caráter excepcional, quando o autor representa uma atração à parte.

10 Os dois meios de comunicação são dotados de um poder de influência diferente: as notícias televisivas são demasiado breves, rápidas, heterogêneas, numa dimensão temporal limitada; isto é, são excessivamente fragmentárias, para terem um efeito de agenda significativo, o que não quer dizer que não possuam algum efeito. Podemos supor, então, que, para os consumidores de informação televisiva, o aumento de consumo não se traduz num maior efeito de agendasetting, contrariamente ao que ocorre com os grandes consumidores de informação escrita, pois a informação escrita fornece aos leitores uma indicação de importância sólida, constante e visível. 
Na técnica redacional, o editorial, ao contrário da notícia, não obedece a qualquer padrão formal. Seu tom, quando não assinado, é tão impessoal quanto possível; quando assinado, deve ser mais pessoal. Geralmente, apresenta duas partes (muitas vezes interpoladas); a expositiva e a explanatória. Na primeira, apresenta-se o tema: acontecimento, notícia, ideia, situação. Na segunda, desenvolve-se o raciocínio opinativo em torno do exposto na primeira.

Enfim, o editorial é aquele espaço que se constitui na reflexão da sociedade civil e que tem como finalidade a definição de alguns princípios editoriais referenciados no interesse público. São vozes que se constituem em nome e/ou a partir de várias causas; falam em nome do coletivo; e definem-se como portavozes de categorias sociais; magistrados no exame de causas, legisladores sociais, pedagogos na análise e na sistematização de fatos que são devolvidos ao leitor na forma de ponto de vista etc. Poder-se-ia dizer que as informações do editorial constituem, através das mais diferentes manobras figurativas ${ }^{11}$, uma certa noção de âncora. Não porque fazem o trabalho de especificar as grandes características do que trata a edição, mas porque, ao mesmo tempo que são anunciantes de reclames da edição, apresentam-se como aquelas que dão o tom avaliativo de como o mundo vai ser ali indicado e, ao mesmo, construído.

Contudo, essas são características do nosso jornalismo, influenciadas pela estrutura dos jornais americanos, que diferem dos modelos europeus, como analisam R. Burbage, J. Cazemajon e A. Kaspi (1973, p. 187):

\footnotetext{
O tratamento da informação e a apresentação das notícias editoriais são, todavia, diferentes do que estamos habituados nos jornais europeus.Se a escolha dos acontecimentos que se colocam na "Página 2" representa, como entre nós, a orientação tomada pela redação, se esta relação das notícias editoriais corresponde, corretamente, a uma expressão da opinião; diferentemente dos jornais europeus, que confundem muito frequentemente comentários e notícias, os diários americanos separam o acontecimento das reflexões que o inspiram. Esforçam-se em apresentar
} 
as notícias tais como são transmitidas pelos despachos das agências ou pelos enviados especiais, evitando qualquer tomada de posição ou qualquer conclusão, supondo-se, assim, que o jornalista, ao apresentar um fato qualquer, possa ser objetivo. $O$ dado da atualidade, oferecido desta forma aos leitores, constituirá objeto de comentários nos editoriais publicados pelos diários. Enfim, é por eles que um jornal toma posição.

É, por fim, o editorial um campo de luta, porque nele se trava um debate entre vozes: aquelas pelas quais se apresenta o sujeito da enunciação, tentando dar formato ao mundo, gerando um pseudo ambiente, e aquelas outras, a quem ele se presta a legitimar ou, ainda, a quem enfrenta como adversários a serem combatidos, vencidos e silenciados. Tais vozes, reais e encenadas, fazem operar a linguagem em campo de guerra ${ }^{12}$, não só no sentido de combates entre sujeitos sociais mas também advindo das relações de força entre sistemas discursivos. Dessa forma, na topografia jornalística, o editorial é um território estratégico, porque ali se faz a construção da guerra, especialmente os processos de intervenção do campo midiático no próprio processo de instituição do real e também porque faz agirem os atores sociais.

Desse modo, levando-se em consideração todas as características, funções e "poderes" do editorial, aliado ao elemento teórico que norteia este trabalho, realizamos o levantamento da agenda midiática (focalizando os principais temas políticos, econômicos e sociais presentes nos meios de comunicação durante o período eleitoral de 1998) presente especificamente nos editoriais (não assinados) dedois dos jornais de maior relevância no país - O Estado de S. Paulo e a Folha de S. Paulo -, assim como fizemos a comparação entre as duas agendas temáticas, para notarmos os temas que foram relevantes em ambos os jornais (semelhanças e diferenças) e como se configuraram os noticiários/editoriais e o comportamento dos temas no decorrer das eleições presidenciais de 1998. 


\section{Procedimentos}

Foram selecionados para a pesquisa dois jornais que, segundo o IVC (Instituto Verificador de Circulação), estão entre os líderes de seus segmentos, tanto no mercado nacional quanto no paulista: Folha de S. Paulo (Folha) e O Estado de S. Paulo (Estadão). Embora a seleção não tenha produzido, como seria desejável, uma amostra nacional, deve-se salientar que os dois veículos escolhidos circulam nacionalmente, com grande penetração entre os tomadores de decisão e formadores de opinião, sendo usualmente considerados como segunda opção de leitura nos principais Estados brasileiros.

O procedimento de coleta de dados foi realizado por meio da análise de conteúdo dos jornais editados nos meses de julho, agosto e setembro de 1998 (período correspondente ao de eleições presidenciais), especificamente durante as terças, quintas e domingos - por serem dias de maiores tiragens dos jornais, na época da pesquisa (especialmente os domingos), como também pelo fato de serem os dias em que se realizavam os HGPE (horários gratuitos políticos eleitorais) dos presidenciáveis. Nesses dias, analisamos todos os editoriais não assinados publicados, com o mesmo grau de atenção. Dessa forma, foram investigadas, somando-se ambos os jornais, 68 edições diárias, ou seja, 24 em julho, 24 em agosto e 20 em setembro; supondo-se que os veículos possuem em média três editoriais não assinados por edição, temos que foram estudados em torno de 204 editoriais, cuja análise de conteúdo resultou numa coleta de 2.079 categorias/símbolos -720 da Folha e 1.359 do Estadão. 


\section{Relação entre os jornais, os meses, a quantidade}

e a porcentagem dos temas

Folha

J
A

$\mathbf{S}$
Estadão

J
A

S*

\begin{tabular}{|c|c|c|c|c|c|c|}
\hline ECONOMIA & 34,83 & 44,48 & 45,26 & 24,68 & 37,6 & 47,32 \\
\hline POLÍTICA & 31,46 & 28,13 & 41,57 & 46,53 & 31,3 & 43,15 \\
\hline ELEIÇÕES & 15,35 & 16,73 & 6,31 & 8,17 & 8,47 & 2,08 \\
\hline SOCIAL & 16,47 & 10,64 & 6,84 & 15,8 & 21,95 & 7,44 \\
\hline OUTROS & 1,87 & ---- & ---- & 4,79 & 0,65 & ---- \\
\hline \multirow[t]{2}{*}{ TOTAL } & 100 & 100 & 100 & 100 & 100 & 100 \\
\hline & 267 & 263 & 190 & 563 & 460 & 336 \\
\hline
\end{tabular}

$* \mathbf{J}=$ julho; $\mathbf{A}=$ agosto; $\mathbf{S}=$ setembro $\quad \mathbf{N}=\mathbf{2 . 0 7 9}$

Com o objetivo de reduzir os problemas de validação ${ }^{13}$ típicos da análise de conteúdo e relacionados ao grau de confiabilidade no processo de codificação, foram definidos alguns procedimentos-padrão. A unidade de registro (o que se conta) escolhida foi o tema (análise temática), considerado pela literatura 
pertinente às técnicas de análise de conteúdo como o mais adequado para registrar opiniões, atitudes, valores, crenças e tendências ${ }^{14}$. Quanto à unidade de contexto (onde se conta), foi adotado o seguinte critério: o parágrafo. Nesse caso, se convencionou que um tema estaria configurado se presente em pelo menos $25 \%$ do total de parágrafos do texto. Com o objetivo de eliminar ou reduzir interpretações subjetivas, a regra de enumeração (como se conta) foi baseada na presença de temas-eixo definidos previamente numa lista organizada e composta por três categorias (política, economia e social) e 49 temas e subtemas (agrupados nas categorias citadas). Cada tema ou subtema foi contado uma única vez, por ocorrência na unidade de contexto, sendo, porém, permitida a codificação múltipla (a presença de mais de um tema ou subtema na unidade de contexto). Após a codificação, foi organizada uma lista com os dez primeiros temas e subtemas - em relação aos conjuntos de dados nos editoriais dos jornais. Os temas mais repetidos nas nove listas geradas pelo procedimento anterior foram considerados os principais pontos da agenda, no período considerado aqui, dos veículos pesquisados.

A distribuição dos editoriais por categoria temática revela que os temas de cunho político - repetindo o padrão encontrado nas manchetes de primeira página, que no recorte deste trabalho não foram analisadas - , foram mais frequentes na Folha do que no Estadão. Além disso, ambos os veículos dedicaram praticamente a mesma atenção aos tópicos econômicos e sociais. Em compensação, no Estadão, o percentual de matérias publicadas na categoria Todas as outras (que reúne os assuntos internacionais e os tópicos não incluídos na lista de temas e subtemas previamente organizada para a pesquisa) foi, como nas manchetes de primeira página, comparativamente muito maior ao da Folha. De qualquer maneira, como ocorreram com as manchetes de primeira página, os assuntos econômicos predominaram nos editorais dos dois veículos.

14 Ver Bardin (1977, p. 105 e seguintes). O tema, para os propósitos deste trabalho, foi definido de acordo com Berelson (1971): "uma afirmação acerca de um assunto. Quer dizer, uma frase, ou uma frase composta, habitualmente um resumo ou uma frase condensada, por inferência da qual pode ser afetado um vasto conjunto de formulações singulares". 
Quanto aos temas mais frequentes (16) nos editoriais dos diários aqui considerados, os dois jornais compartilharam 37,50\%, ou seja, seis deles (crise financeira; campanha eleitoral; governo federal; reforma do Estado; ajuste fiscal; e saúde pública), todos presentes também nas manchetes de primeira página daqueles veículos, com exceção do tema reforma do Estado. Entre os dez temas não compartilhados $(62,50 \%)$, um deles (violência/segurança) esteve presente entre as dez manchetes mais frequentes de ambas publicações, enquanto seis deles (educação; pobreza/fome; sistema bancário; impostos; taxas e tributos; privatização; e reforma agrária/sem-terra) figuraram na lista de pelo menos um dos jornais. Dessa maneira, apenas três dos temas não compartilhados (globalização; ciência e tecnologia; e comércio exterior) estiveram ausentes das listas dos temas mais frequentes nas manchetes dos dois veículos. Em outras palavras, $81,25 \%$ dos assuntos explorados pelos editoriais dos dois diários tinham correspondência temática com as manchetes de primeira página mais frequentes de pelo menos um dos jornais aqui considerados, indicando, assim, uma forte correlação entre ambos. 
Lista dos temas e subtemas mais frequentes nos editoriais

\begin{tabular}{|c|c|c|c|c|c|}
\hline \multicolumn{3}{|c|}{ FOLHA DE S. PAULO } & \multicolumn{3}{|c|}{ O ESTADO DE S. PAULO } \\
\hline ordem & TEMAS E SUBTEMAS & $\%$ & ordem & TEMAS E SUBTEMAS & $\%$ \\
\hline \multirow[t]{5}{*}{10} & CAMPANHA ELEITORAL & 13,9 & $1^{\circ}$ & CRISE FINANCEIRA & 11,1 \\
\hline & Campanha presidencial & 3,3 & $2^{\circ}$ & CAMPANHA ELEITORAL & 6,5 \\
\hline & Campanhas estaduais & 0,8 & & Campanha presidencial & 0,9 \\
\hline & $\begin{array}{l}\text { Pesquisas } \\
\text { (corrida eleitoral presidencial) }\end{array}$ & 0,8 & & Campanhas estaduais & 0,0 \\
\hline & Temas diversos de campanha & 9,0 & & $\begin{array}{l}\text { Pesquisas } \\
\text { (corrida eleitoral presidencial) }\end{array}$ & 0,9 \\
\hline $2^{\circ}$ & CRISE FINANCEIRA & 12,3 & & Temas diversos de campanha & 4,6 \\
\hline $3^{\circ}$ & SAÚDE PÚBLICA & 4,9 & $3^{\circ}$ & EDUCAÇÃO & 5,6 \\
\hline $4^{\circ}$ & REFORMA DO ESTADO & 4,1 & $4^{\circ}$ & IMPOSTOS, TAXAS E TRIBUTOS & 4,6 \\
\hline \multirow[t]{5}{*}{$5^{\circ}$} & GOVERNO FEDERAL & 3,3 & & PRIVATIZAÇÃO & 4,6 \\
\hline & Presidente & 0,0 & & SAÚDE PÚBLICA & 4,6 \\
\hline & Executivo & 3,3 & & REFORMA AGRÁRIA/SEM-TERRA & 4,6 \\
\hline & Legislativo & 0,0 & & AJUSTE FISCAL & 4,6 \\
\hline & Judiciário & 0,0 & $9^{\circ}$ & GOVERNO FEDERAL & 3,7 \\
\hline $6^{\circ}$ & POBREZA/FOME & 2,5 & & Presidente & 0,0 \\
\hline 70 & VIOLÊNCIA/SEGURANÇA & 2,5 & & Executivo & 2,8 \\
\hline \multirow[t]{4}{*}{$8^{\circ}$} & AJUSTE FISCAL & 2,5 & & Legislativo & 0,9 \\
\hline & Sistema bancário & 2,5 & & Judiciário & 0,0 \\
\hline & Globalização & 2,5 & $10^{\circ}$ & REFORMA DO ESTADO & 2,5 \\
\hline & Ciência e tecnologia & 2,5 & & $\begin{array}{l}\text { Comércio exterior } \\
\text { (importação/exportação) }\end{array}$ & 2,5 \\
\hline
\end{tabular}

Obs.: (1) Os temas em comum estão digitados em maiúscula; (2) Na classificação, foi descartada a categoria "Todas as outras"; (3) Os percentuais estão calculados em relação ao total de temas de cada veículo. 


\section{Conclusão}

Nessas considerações finais, é necessário notarmos que esse trabalho se preocupou exclusivamente com apenas uma das três agendas que compõem o agenda-setting (agenda midiática, agenda pública, agenda governamental/ política), ou seja, o enquadramento da realidade difundido pela agenda midiática.

Nesse momento, podemos dizer que há diferenças não só entre as formas de agendar os temas nos diferentes meios de comunicação mas também entre os veículos do mesmo gênero. Quando escolhemos os dois jornais analisados nesta pesquisa, o primeiro fator prevalecente foi o estarem entre os periódicos diários de maiores tiragens no país; em segundo lugar, por serem estrutural e "ideologicamente", podermos dizer, diferentes. Um tido como mais liberal (Folha) e o outro tido como conservador (Estadão). Por essas características, pudemos notar mais algumas diferenças entre ambos: o Estadão foi, entre os dois veículos, o que mais ênfase deu às categorias pré concebidas - 1.359, contra 720 na Folha. Na Folha, ao contrário do que observado no Estadão, mesmo com um ou outro tema tendo predominado, a diferença no número de exibições não era tão grande de um para o outro. Importante também foi notar a forma propagandística de se oferecerem os temas e os assuntos - e cada veículo teve uma forma peculiar nessa oferta. Enquanto a Folha enquadrou a realidade -e, assim, os temas - sempre pelos fins que aação possuía, por outro lado, o Estadão concebeu a realidade pela ação em si, independente de seu fim. Ao finalizarmos a análise dos dados, pudemos ver claramente um aspecto interessante: o da existência de uma retroalimentação entre os assuntos do tema prevalecente. Pois, quando notamos em especial o tema Economia - que, com exceção do mês de julho, no Estadão, foi o predominante no período escolhido em ambos os jornais. Ou seja, durante o período eleitoral,não houve um assunto que predominasse todo o tempo, mas vários assuntos apareceram; por isso, a ideia de retroalimentação, pois, quando um assunto diminuía sua intensidade de aparições, outro surgia e predominava durante um tempo, e assim por diante. 
Dessa forma, podemos realmente afirmar que esse foi um período eleitoral no qual não se discutiu eleição, apesar deter sido um pleito excepcional, pois era a primeira vez que poderia haver a reeleição em cargos majoritários. De qualquer maneira, a agenda dos mass media, nesse período, se concentrou nos aspectos econômicos, especialmente na crise das economias. Esse pode ter sido um dos fatores pelo quais se ofuscaram os temas eleitorais, mas não os políticos, especialmente quando se tratava de assuntos relacionados às ações administrativas do governo federal ou do presidente Fernando Henrique Cardoso. 


\section{Referências}

ALSINA, M. R. La construcción de la Noticia. Barcelona: Paidós, 1989.

BARTHES, Roland. O rumor da língua. Lisboa: Signos, 1987.

BARDIN, L. Análise de conteúdo. Lisboa: Edições 70, 1977.

BERELSON, B. Content analysis in communication research. New York: Hafner, 1971.

BERGER, P.; LUCKMANN, T. A construção social da realidade: tratado de sociologia do conhecimento. Petrópolis: Vozes, 1976.

BURBAGE, R.; CAZEMAJON, J.; KASPI, A. Os meios de comunicação nos Estados Unidos (imprensa, rádio e televisão). Rio de Janeiro: Agir, 1973.

CANCLINI, G. N. Culturas híbridas. México:Grijalbo, 1990. .Consumidores e cidadãos. Rio de Janeiro: UFRJ, 1995.

COHEN, Bernard C. The press and foreign policy. New York: Princeton University Press, 1963.

DUVERGER, M. Os partidos políticos. Rio de Janeiro: Zahar; Brasília: UnB, 1980.

FAUSTO NETO, A. "Vozes do impeachment". In MATOS, H. (Org.). Mídia, eleições e democracia. São Paulo: Scritta, 1994.

FORMIGA, F.de O. N.. A evolução da hipótese de agenda-setting, Dissertação (Mestrado) - Universidade de Brasília, 2006. Mimeografado.

GOFFMAN, E. Les cadres de l'experience. Paris: Minuit, 1991.

LASSWELL, H. A linguagem da política. Brasília: UnB, 1982.

McCOMBS, M. E. "Elaborating the agenda-setting influence of mass communication". Bulletin of the Institute for Communication Research, Keio University, 1976. 
McCOMBS, M. E.;SHAW, D. L. "The agenda-setting function of mass media". Public Opinion Quarterly, v. 36, 1972.

SAPERAS, E. Os efeitos cognitivos da comunicação de massa. Porto: ASA, 1987.

SARTORI, G. Partidos e sistemas partidários. RJ: Zahar Editores; Brasília: UnB, 1982.

SHAW, E. "Agenda-setting and mass communication theory". Gazette-International Journal for Mass Communication Studies, v. XXV, n. 2, 1979.

TRAQUINA, N. "O paradigma do agenda-setting. Redescoberta do poder do jornalismo". Revista de Comunicação e Linguagens, Lisboa, n. 21-22, 1995. 